\title{
The use of ultrasonography in infantile hypertrophic pyloric stenosis: do the patient's age and weight affect pyloric size and pyloric ratio?
}

\author{
Ümit Yaşar Ayaz ${ }^{1}$, Mehmet Ercüment Döğen ${ }^{1}$, Alper Dilli² ${ }^{2}$ Sevin Ayaz ${ }^{3}$, Arman Api $^{4}$
}

${ }^{1}$ Department of Radiology, Mersin Women's and Children's Hospital, Mersin, ${ }^{2}$ Department of Radiology, Dışkap1 Yıldırım Beyazıt Training and Research Hospital, Ankara, ${ }^{3}$ Department of Nuclear Medicine, Mersin State Hospital, Mersin, ${ }^{4}$ Department of Pediatric Surgery, Mersin Women's and Children's Hospital, Mersin, Turkey

\begin{abstract}
Aims: We aimed to obtain pyloric measurements of our patients with infantile hypertrophic pyloric stenosis (IHPS) using ultrasonography (US) and to evaluate the correlations between age, weight and pyloric size, pyloric ratio (PR). Material and methods: We designed a retrospective study including 20 term infants with surgically proven IHPS and studied the ultrasonographically obtained pyloric muscle thickness (PMT), pyloric diameter (width) (PD), pyloric length (PL) and PR (PMT/PD) to determine if there were statistically significant associations between patient age/weight and pyloric measurements. Results: The mean age of the infants was 38.7 \pm 17.3 days (range, 9-76 days) and their mean weight was $3688.5 \pm 772.7 \mathrm{~g}$ (range, 2810 $6000 \mathrm{~g}$ ), at referral. Mean PMT was 4.98 $\pm 1.04 \mathrm{~mm}$ (range, 3.5-6.8 mm). Mean PD was 14.04 $\pm 2.39 \mathrm{~mm}$ (range, 10-18 mm). Mean PL was 22.16 $\pm 4.02 \mathrm{~mm}$ (range, 16-31.5 mm) and mean PR was $0.35 \pm 0.04$ (range, 0.29-0.42). The correlation between age and PMT $(r=0.654, p<0.05)$ and the correlation between age and PD $(r=0.747, p<0.05)$ were significant. Age and weight were not significantly correlated with PR ( $>>0.05)$. Conclusions: The PMT and PD are age dependent parameters. The PR is age and weight independent and therefore, when combined with PMT, PD and PL, it can be useful in the diagnosis of IHPS in infants with early onset disease and/or in those with a lower weight.
\end{abstract}

Keywords: ultrasonography, infant, pyloric stenosis, age, body weight.

\section{Introduction}

Infantile hypertrophic pyloric stenosis (IHPS) is a pathologic condition characterized by obstruction to gastric emptying as a result of the abnormal thickening of the antropyloric portion of the stomach in early infancy [1]. In other words, IHPS is an idiopathic hypertrophy and hyperplasia of circular muscle fibers of pylorus with proximal extension into the gastric antrum [2]. Its incidence is about 3:1,000 newborns and it is four to five times more frequent in males than in females. Manifesta-

Received 17.08.2014 Accepted 08.10.2014

Med Ultrason

2015, Vol. 17, No 1, 28-33

Corresponding author: Dr. Ümit Yaşar Ayaz, M.D.

Mersin Kadın Doğum ve Çocuk Hastalıkları

Hastanesi, Radyoloji Bölümü,

33240 Halkkent, Mersin, Türkiye

Phone: +90 3242230701 ,

Mobile: +90 5377639442

Fax: +90 3242230722

E-mail: umityasarayaz@yahoo.com tions usually occur between two to eight weeks of life [2]. However, a 28-month-old male child with late-onset symptoms of hypertrophic pyloric stenosis has also been reported [3]. IHPS should be considered in any vomiting infant [4], though gastroesophageal reflux (GER), pylorospasm, hiatal hernia, and preampullary duodenal stenosis can also manifest with nonbilious vomiting [1]. The use of ultrasonography (US) in the diagnosis of IHPS evidenced an increase over time, compared to earlier periods [4-6]. Only in a few studies was the pyloric ratio (PR) evaluated and it was found to be an additional and useful US parameter in the diagnosis of IHPS in infants with different age and weights [7], including premature infants [8]. Despite the controversial relationship of age and weight with basic pyloric size measurements which is still a subject of debate today [8-11], PR seems to be a more stable parameter because it does not vary with age and weight $[7,8]$.

Our primary goal in this retrospective study was to evaluate the correlation between the main clinical (weight and age of the infants) and US parameters (py- 
loric size and PR). We consider that the results obtained from our study can add newer information for diagnosis of IHPS in infants with different ages and weights, including the ones with early onset disease and/or with lower weight.

\section{Material and methods}

\section{Patients and ultrasonographic parameters}

Between November 2007 and August 2014 we retrospectively reviewed the medical records and US examinations of 20 consecutive infants out of 24, with ultrasonographically detectable IHPS. Four patients were excluded from the study because their surgical results and weights were not available. Age and weight of the infant at referral, ultrasonographically measured pyloric muscle thickness (PMT), pyloric diameter (width) (PD), pyloric length (PL) and PR were evaluated. The PR was calculated for each patient as PMT divided by PD [7]. Patient's clinical status after surgery was also checked. All the patients' parents were informed about the procedures, oral consent was obtained for US examinations and written informed consent was obtained before contrast studies of the upper gastrointestinal (UGI) tract and surgery. All the procedures were performed according to the World Medical Association Declaration of Helsinki (revised in 2000, Edinburgh).

Sixteen males and four females, term infants, were included. In all patients, the diagnosis of IHPS was initially made by US examinations and the clinical outcomes of the patients were obtained. Contrast radiographs of UGI tract were not obtained as a standard initial diagnostic tool to avoid unnecessary radiation exposure. In eight patients, contrast studies with minimal X-ray exposure time and dose were performed before surgery to evaluate anatomically the UGI tract. Besides US, no other crosssectional imaging modalities, such as computed tomography or magnetic resonance imaging were performed. In all cases, US diagnosis of IHPS was confirmed with open surgery. All of the transabdominal US examinations were performed by the same pediatric radiologists with 10 years' experience in pediatric US practice, using standard techniques. Abdominal US was performed in 10 cases with Logiq 200 Pro US device (General Electric Medical Systems, Seongnam, Gyeonggi-do, Korea) and in the other 10 cases with Logiq 7 US device (GE Healthcare Japan Corporation, Tokyo, Japan), using 3-3.5 MHz convex-array and 7.5-8 MHz linear-array transducers with infants in supine and right posterior oblique positions just after a limited breast or bottle feeding. We avoided overdistension of stomach during feeding. Upper abdominal quadrants were the main areas of interest; however, lower abdominal quadrants were also evaluated.

\section{Ultrasonographic criteria}

The PMT was measured on transverse images, from the outermost border of the muscle to the outermost border of mucosa, which includes only one muscle layer (fig 1). For making a definitive diagnosis of IHPS in our department the cut-off value for pyloric muscle wall thickness $\geq 3.0 \mathrm{~mm}$ is accepted as the main quantitative criteria $[2,7,12-15]$. The PD was measured on transverse images by placing the calipers at the outermost border of the opposing muscle layers, in which mucosa and narrowed lumen were also included. The PL was measured from the beginning of the duodenal lumen to the gastric antrum on longitudinal images (fig 2, fig 3). Numeric values were expressed as means \pm standard deviations with range values. We used ultrasonographic target sign and cervix sign as qualitative criteria [2]. We also performed a standardized dynamic US examination [16] to support the diagnosis. During dynamic examination, we functionally evaluated food passage through the pyloric canal and peristaltism, while looking for secondary GER and, absent or delayed stomach emptying.

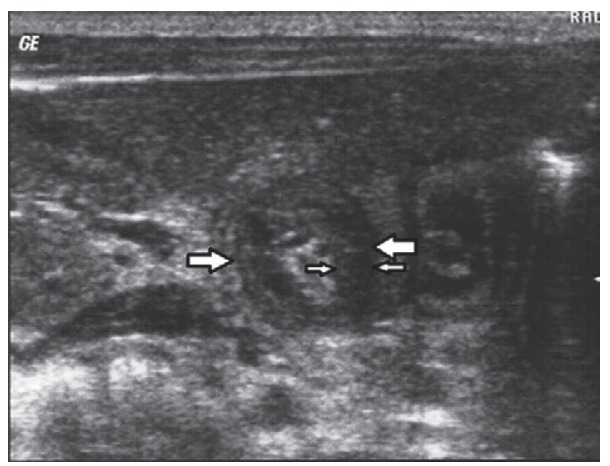

Fig 1. Target sign on transverse sonogram of hypertrophic pyloric stenosis in a 42-day-old male infant with $7.5 \mathrm{MHz}$ linear probe. The thickness of the hypoechoic muscle layer (thin white arrows) was divided by the pyloric diameter (thick white arrows) to calculate the pyloric ratio, which was 0.30 in this patient.

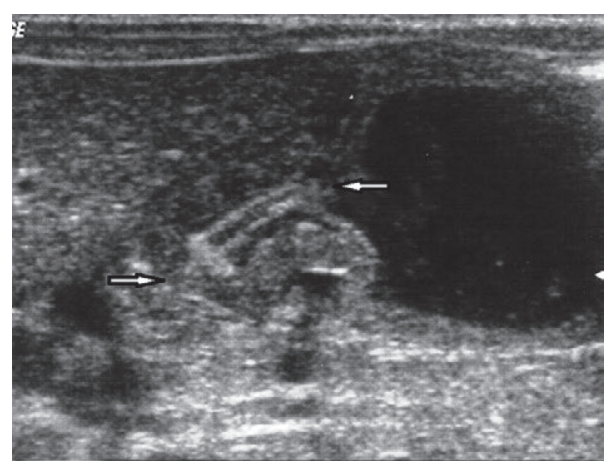

Fig 2. Longitudinal view of hypertrophic pylorus with 7.5 MHz linear probe (white arrows: pyloric length). Same case as in fig 1. 
The use of ultrasonography in infantile hypertrophic pyloric stenosis

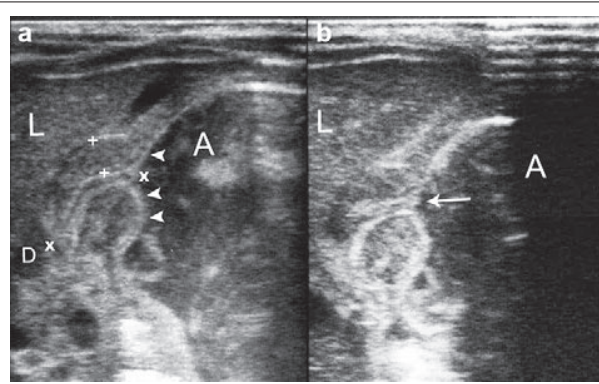

Fig 3. a, b. Longitudinal views of hypertrophic pyloric stenosis in a 30-day-old male infant with 7.5 MHz linear probe (white arrowheads: cervix sign, white arrow: antral nipple sign, + calipers: hypoechoic pyloric muscle, x calipers: measurement of pyloric length. A: antrum filled with gastric fluid, L: liver, D: duodenal cap).

\section{Statistical analysis}

The correlations between clinical parameters (weight and age of the infants) and US parameters (PMT, PD, PL, PR) were evaluated by Pearson correlation test. The correlation between weight and age of the infants was evaluated by the Pearson correlation test. Sonographical parameters (PMT, PD, PL, PR) were compared according to gender by using independent samples $t$ test. P values $<0.05$ were considered as statistically significant. All analyses were done with SPSS software (version 16.0: SPSS Inc, Chicago, IL).

\section{Results}

Male to female ratio was $4: 1$. Nonbilious vomiting was present in all cases. At referral, the mean age of the infants was $38.7 \pm 17.3$ days (range, 9-76 days) and mean weight of the infants was $3688.5 \pm 772.7 \mathrm{~g}$ (range, 2810-6000 g). In medial parts of right upper quadrants of all cases, US revealed thick and elongated viscus appearance with extensively narrowed lumen, in continuity with stomach, representing hypertrophied pylorus. In all cases, target sign and cervix sign representing widened and elongated pylorus with thickened muscularis propria, were demonstrated with US. In all cases, real-time dynamic examination revealed increased gastric peristaltism, lack of an effective passage through the pylorus, absent or delayed stomach emptying and secondary GER. Mean PMT, PD, PL and PR with their range values are summarized in Table I. 20\% $(n=4 / 20)$ of our patients had a PMT less than $4 \mathrm{~mm}$. The correlation between age and PMT $(r=0.654, p<0.05)$ and the correlation between age and PD $(r=0.747, p<0.05)$ were significant. There was no significant correlation between age and PL or between weight and basic pyloric measurements (PMT, PD, PL) (all $p>0.05$ ). Age and weight were not significantly
Table I. Means \pm standard deviations of pyloric measurements with range values.

\begin{tabular}{ll}
\hline Pyloric muscle thickness $(\mathrm{mm})$ & $4.98 \pm 1.04$ \\
& Range, $3.5-6.8$ \\
Pyloric diameter $(\mathrm{mm})$ & $14.04 \pm 2.39$ \\
& Range, $10-18$ \\
Pyloric length $(\mathrm{mm})$ & $22.16 \pm 4.02$ \\
& Range, $16-31.5$ \\
Pyloric ratio & $0.35 \pm 0.04$ \\
& Range, $0.29-0.42$ \\
\hline
\end{tabular}

Table II. Pearson correlation coefficients and P values regarding the associations between age/weight and pyloric measurements.

\begin{tabular}{lll}
\hline $\begin{array}{l}\text { Pyloric measure- } \\
\text { ments }\end{array}$ & Age & Weight \\
\hline PMT & $\mathrm{r}=0.654, \mathrm{p}<0.05$ & $\mathrm{r}=0.301, \mathrm{p}=0.197$ \\
PD & $\mathrm{r}=0.747, \mathrm{p}<0.05$ & $\mathrm{r}=0.345, \mathrm{p}=0.136$ \\
PL & $\mathrm{r}=0.157, \mathrm{p}=0.508$ & $\mathrm{r}=-0.027, \mathrm{p}=0.909$ \\
PR & $\mathrm{r}=0.088, \mathrm{p}=0.713$ & $\mathrm{r}=0.062, \mathrm{p}=0.794$ \\
\hline
\end{tabular}

$\mathrm{P}$ values $<0.05$ are considered as statistically significant

correlated with PR ( $>>0.05)$. Pearson correlation coefficients and $p$ values regarding the associations between age/weight and pyloric measurements were summarized in Table II. The difference between PMT, PD, PL, PR values of male and female infants were not statistically significant $(\mathrm{p}>0.05)$. All the patients underwent open surgery and procedure of pyloromyotomy was successfully performed. All the patients were discharged from the hospital in good health.

\section{Discussions}

The etiology of IHPS remains unclear. Regardless of the etiological debates [17-20], typically infants with IHPS are clinically normal at birth but during the first few weeks of postnatal life, they develop nonbilious forceful vomiting mostly described as "projectile". Gastric outlet obstruction leads to emaciation and, if left untreated, may result in death $[1,21,22]$. Positive family history of IHPS in infants with nonbilious vomiting with progression over a period of several weeks after birth [2] should alert the physician for the diagnosis of IHPS.

Due to its high sensitivity and specificity without any risk of ionizing radiation and its ability to demonstrate other intraabdominal pathologies that might co-exist, US has been widely used as an imaging tool for IHPS diagnosis prior to surgery $[6,12,13,23-25]$. US was also used in the follow-up of the healing process of medically treated IHPS [26] and in monitoring conservatively treated IHPS cases [16]. The most common US diagnostic sign of IHPS is the target sign (hypoechoic ring of hypertrophied pyloric muscle around centrally located echogenic 
mucosa on cross-section), which can be easily differentiated from the target sign of intussusception in pediatric cases [27] mainly by the relatively smaller diameter of IHPS and the continuity of IHPS with antrum. Other typical findings of IHPS, which we also detected in our patients, are elongated pylorus with thickened muscle, cervix sign (indentation of muscle mass to fluid-filled antrum on longitudinal section), antral nipple sign (redundant pyloric channel mucosa protruding into gastric antrum), exaggerated peristaltic waves and delayed gastric emptying of fluid into duodenum [2]. Besides these signs, there is also a sonographic double-track sign for the diagnosis of IHPS, but it was reported to be seen in cases of pylorospasm, too [28]. However, image or measurement variability is an important clue for diagnosing pylorospasm [29]. In a vomiting infant GER can be diagnosed using US [30], as we could do this in our study. The importance of standardized dynamic US examination was well expressed [16]. For us too, the dynamic examination was essential, since we made the diagnosis of IHPS before surgery by combining our numeric data with real-time functional findings.

After the introduction of US for the diagnosis of IHPS in 1977 [31], a considerable number of US studies have been conducted in order to obtain average pyloric measurements in infants with IHPS. The majority of the authors accepted the cut-off value for PMT as $3.0 \mathrm{~mm}$ in these patients [2,7,12-15]. Though Blumhagen et al $[23,24]$ reported that PMT of $4 \mathrm{~mm}$ or more is diagnostic for IHPS, an important percentage of our patients with IHPS had a PMT less than $4 \mathrm{~mm}$. Assefa [13] reported the mean PMT, PL and PD as $4.46 \mathrm{~mm}, 19.1 \mathrm{~mm}$ and 14.05 $\mathrm{mm}$, respectively. In the cross-sectional study of Alehossein et al [12], the mean PMT, PL and PD with their range values were $4.94 \pm 0.65 \mathrm{~mm}$ (range: $3-6.5 \mathrm{~mm}$ ), $20.22 \pm 2.33 \mathrm{~mm}$ (range: $16-28 \mathrm{~mm}$ ) and $13.14 \pm 1.97 \mathrm{~mm}$ (range: $8.7-17 \mathrm{~mm}$ ), respectively. Niedzielski et al. [32] reported their mean PMT, PL and PD as $5.41 \mathrm{~mm}, 20.89$ $\mathrm{mm}$ and $14.1 \mathrm{~mm}$, respectively. In our study, pyloric measurements were close to those mentined above.

After we evaluated the results of recent studies, we concluded that the effects of patient age and weight on basic pyloric measurements are still controversial. We compared our results with those in literature. Leaphart et al [9] reported that PMT and PL were significantly decreased in younger $v s$ relatively older newborns with IHPS. This is partially consistent with our results but we found no correlation between age and PL. In the study of Said et al [10] there was a significant relationship between age and PMT and there was no significant relationship between PL and age or weight, which was the same in our study. However unlike us, they also showed a significant relationship between weight and PMT [10]. Iqbal et al [14] reported that age had a positive correlation with PMT which is consistent with our results; however, unlike us they found that weight had a positive correlation with PMT and age positively correlated with PL. In their study including premature infants, Cascio et al [8] found that PMT and PL were not affected by weight and corrected gestational age. Forster et al [11] also found no significant correlation between age, weight or prematurity and sonographical diagnosis of IHPS, regarding PMT and PL. However, in our study, we found a positive correlation with age and PMT. We consider that the differences between the results of above mentioned studies including our study, can be explained by the differences in the study designs (inclusion of infants with relatively homogenious $v s$ heterogenious age spectrum), by diversities in the number of cases in different studies and by US factors. In some studies only relatively younger infants were included [8,9] whereas in others, infants with a relatively wide age spectrum were evaluated $[10,11]$. Relatively a small number of patients in some groups might have caused a decrease in statistical power and the inclusion of a relatively high number of patients with extreme age and weight values with different duration of symptoms in some groups, might have caused the differences in the results. Besides the differences in US devices and techniques used, intraobserver and interobserver differences might have affected pyloric measurements in various study groups.

Despite the above mentioned controversial relationship of age and weight with basic pyloric size measurements, PR seems to be age and weight independent. Lowe et al [7] reported the average PR in normal children $(n=50)$ and in those with IHPS $(n=34)$ as 0.205 and 0.325 , respectively $(\mathrm{p}<0.001)$. Cascio et al [8] calculated PR in 15 premature infants and the median was 0.38 . In our study, mean PR was close to these values in infants with IHPS. Also, both age and weight were not significantly correlated with PR, which was similar to the results of the above mentioned studies [7,8].

A relatively small patient population can be regarded as a limitation of our study. However, as compared with the number of patients in previous studies which particularly focused on PR $[7,8]$, we consider that our study group consisted of an average number of patients. Despite the limited number of patients that could be gathered in our province, our quantitative findings (age and weight on referral, pyloric measurements and PR values) were close to those of other studies reported in literature, reflecting that age and weight distribution of our patients was lacking extreme diversities and was convenient for this study. Our quantitative and qualitative findings also 
demonstrated that we have used an appropriate measuring technique and convenient US devices.

As for the treatment, pyloromyotomy remains the standard of treatment and outcome is excellent [33]. In our study, all the patients underwent surgery and the procedure of pyloromyotomy was successfully performed.

\section{Conclusions}

The PMT and PD are positively correlated with age. The PR is age and weight independent and therefore, when combined with PMT, PD and PL, it can be useful in the diagnosis of IHPS in infants with early onset disease and/or in the ones with lower weight. However, since strict use of measurements without clinical and dynamic correlations is dangerous in IHPS, so a standardized dynamic sonographic examination to support the diagnosis should be performed. US should be the first imaging modality in infants who are clinically suspected to have IHPS, since it allows rapid, real-time evaluation of the patients efficiently, without any exposure to ionizing radiation.

Conflict of interest: the authors declared no conflicts of interest.

Acknowlegments: We cordially and sincerely appreciate the solidarity of Dr. İbrahim Şanlıalp, Dr. Bekir Civilo, Dr. Muhittin Varlı and Dr. Selahattin Toktaş. We cordially appreciate the guidance of Mustafa Ayaz and Ali Öner (Çelemli).

\section{References}

1. Hernanz-Schulman M. Infantile hypertrophic pyloric stenosis. Radiology 2003; 227: 319-331.

2. Dahnert W. Gastrointestinal tract. In: Dahnert W (ed). 6th ed. Radiology Review Manual. Philadelphia: Lippincott Williams and Wilkins 2007: 842-843.

3. Usta Y, Uslu N, Gürakan F, et al. Geç bulgu veren hipertrofik pilor stenozu: bir vaka takdimi. Çocuk Sağlığı ve Hast Derg 2007; 50: 199-200.

4. Ein SH, Masiakos PT, Ein A. The ins and outs of pyloromyotomy: what we have learned in 35 years. Pediatr Surg Int 2014; 30: 467-480.

5. Hulka F, Campbell TJ, Campbell JR, Harrison MW. Evolution in the recognition of infantile hypertrophic pyloric stenosis. Pediatrics 1997; 100: E9.

6. Taylor ND, Cass DT, Holland AJ. Infantile hypertrophic pyloric stenosis: has anything changed? J Paediatr Child Health 2013; 49: 33-37.

7. Lowe LH, Banks WJ, Shyr Y. Pyloric ratio: efficacy in the diagnosis of hypertrophic pyloric stenosis. J Ultrasound Med 1999; 18: 773-777.
8. Cascio S, Steven M, Livingstone H, Young D, Carachi R. Hypertrophic pyloric stenosis in premature infants: evaluation of sonographic criteria and short-term outcomes. Pediatr Surg Int 2013; 29: 697-702.

9. Leaphart CL, Borland K, Kane TD, Hackam DJ. Hypertrophic pyloric stenosis in newborns younger than 21 days: remodeling the path of surgical intervention. J Pediatr Surg 2008; 43(6):998-1001.

10. Said M, Shaul DB, Fujimoto M, Radner G, Sydorak RM, Applebaum H. Ultrasound measurements in hypertrophic pyloric stenosis: don't let the numbers fool you. Perm J 2012; 16: 25-27.

11. Forster N, Haddad RL, Choroomi S, Dilley AV, Pereira J. Use of ultrasound in 187 infants with suspected infantile hypertrophic pyloric stenosis. Australas Radiol 2007; 51: 560-563.

12. Alehossein M, Hedayat F, Salamati P, Khavari HA, Mollaeian M. The validity of ultrasound in diagnosing hypertrophic pyloric stenosis. Pak J Med Sci 2009; 25: 65-68.

13. Assefa G. Sonographic diagnosis of hypertrophic pyloric stenosis: preliminary experience. Ethiop Med J 2002; 40: $149-154$

14. Iqbal CW, Rivard DC, Mortellaro VE, Sharp SW, St Peter SD. Evaluation of ultrasonographic parameters in the diagnosis of pyloric stenosis relative to patient age and size. $\mathrm{J}$ Pediatr Surg 2012; 47: 1542-1547.

15. O'Keeffe FN, Stansberry SD, Swischuk LE, Hayden CK $\mathrm{Jr}$. Antropyloric muscle thickness at US in infants: what is normal? Radiology 1991; 178: 827-830.

16. Riccabona M, Weitzer C, Lindbichler F, Mayr J. Sonography and color Doppler sonography for monitoring conservatively treated infantile hypertrophic pyloric stenosis. J Ultrasound Med 2001; 20: 997-1002.

17. Gezer HO, Oguzkurt P, Temiz A, Hicsonmez A. Hypertrophic pyloric stenosis in twins; genetic or environmental factors. Clin Genet 2014 Apr 12. doi: 10.1111/cge.12399.

18. Lund M, Pasternak B, Davidsen RB, et al. Use of macrolides in mother and child and risk of infantile hypertrophic pyloric stenosis: nationwide cohort study. BMJ 2014; 348: g1908.

19. Svenningsson A, Svensson T, Akre O, Nordenskjöld A. Maternal and pregnancy characteristics and risk of infantile hypertrophic pyloric stenosis. J Pediatr Surg 2014; 49: 1226-1231.

20. de Laffolie J, Turial S, Heckmann M, Zimmer KP, Schier F. Decline in infantile hypertrophic pyloric stenosis in Germany in 2000-2008. Pediatrics 2012; 129: e901-e906.

21. Fisk AL. I. Hypertrophic Stenosis of the Pylorus in Infants. Ann Surg 1906; 44: 1-15.

22. Jlidi S, Ben Youssef D, Ghorbel S, et al. Infantile hypertrophic pyloric stenosis. Report of 142 cases. Tunis Med 2008; 86: 63-67.

23. Blumhagen JD, Noble HG. Muscle thickness in hypertrophic pyloric stenosis: sonographic determination. AJR Am J Roentgenol 1983; 140: 221-223.

24. Blumhagen JD, Coombs JB. Ultrasound in the diagnosis of hypertrophic pyloric stenosis. J Clin Ultrasound 1981; 9: 289-292. 
25. Kovalivker M, Erez I, Shneider N, Glazer E, Lazar L. The value of ultrasound in the diagnosis of congenital hypertrophic pyloric stenosis. Clin Pediatr 1993; 32: 281-283.

26. Yamamoto A, Kino M, Sasaki T, Kobayashi Y. Ultrasonographic follow-up of the healing process of medically treated hypertrophic pyloric stenosis. Pediatr Radiol 1998; 28: 177-178.

27. Ayaz UY, Dilli A, Ayaz S, Api A. Ultrasonographic findings of intussusception in pediatric cases. Med Ultrason 2011; 13: 272-276.

28. Cohen HL, Blumer SL, Zucconi WB. The sonographic double-track sign: not pathognomonic for hypertrophic pyloric stenosis; can be seen in pylorospasm. J Ultrasound Med 2004; 23: 641-646.

29. Cohen HL, Zinn HL, Haller JO, Homel PJ, Stoane JM. Ultrasonography of pylorospasm: findings may simulate hypertrophic pyloric stenosis. J Ultrasound Med 1998; 17: 705-711.

30. Fufezan O, Farcau D, Valean C, Asavoaie C, Anca I. Gastroesophageal reflux in infants with persistent/recurrent wheezing-an ultrasonographic study. Med Ultrason 2008; 10: 39-42.

31. Teele RL, Smith EH. Ultrasound in the diagnosis of idiopathic hypertrophic pyloric stenosis. N Engl J Med 1977; 296: 1149-1150.

32. Niedzielski J, Kobielski A, Sokal J, Krakós M. Accuracy of sonographic criteria in the decision for surgical treatment in infantile hypertrophic pyloric stenosis. Arch Med Sci 2011; 7: $508-511$.

33. Aspelund G, Langer JC. Current management of hypertrophic pyloric stenosis. Semin Pediatr Surg 2007; 16: 27-33. 